\title{
FILM HYDROGELS ON THE BASIS OF POLYVINYLPYRROLIDONE COPOLYMERS WITH REGULATED SORPTION-DESORPTION CHARACTERISTICS
}

\author{
Volodymyr Skorokhoda $1 .{ }^{*}$, Yuriy M elnyk ${ }^{1}$, Natalia Semenyuk $^{1}$, \\ Nataliya Ortynska, Oleh Suberlyak ${ }^{1}$
}

https://doi.org/10.23939/chcht11.02.171

\begin{abstract}
The hydrogel film composites of biomedical purpose based on copolymers of polyvinylpyrrolidone with 2-hydroxyethylmethacrylate have been synthesized. The influence of filler nature, quantity and composition on the regularities of obtaining, structure and properties of hydrogels have been determined. Synthesized hydrogel composites are recommended to be used for the controlled drug release systems.
\end{abstract}

Keyword: hydrogel, polyvinylpyrrolidone, 2-hydroxyethylmethacrylate, filler, sorption, release.

\section{Introduction}

Cross-linked copolymers of methacrylate with functional active polymers, in particular polyvinylpyrrolidone (PVP), are effectively used for biomedical purposes $[1,2]$, including using them as films for wounds and burns healing and as membranes [3]. An effective way of copolymers properties modification is an introduction of a filler into their composition at the polymerization stage [4]. The polymer materials obtained by polymerization filling have basic properties which are significantly different from the matrix properties [5]. In essence it is a universal creation principle for polymeric composites with a new complex of physical and mechanical properties which are determined by the system micro heterogeneity and polymer - filler interface interactions. At the same time, the composite material properties depend on the properties of the filler practically in the same way as on the initial polymer.

The polymerization filling method allows obtaining composite materials with an uniform distribution of the filler in the polymer matrix, which provides reproducible properties of composites. The presence of polymer pellicle

\footnotetext{
${ }^{1}$ Lviv Polytechnic National University, 12, S. Bandera St., 79013 Lviv, Ukraine

*vskorokhoda@yahoo.com

(C) Skorokhoda V., Melnyk Y., Semenyuk N., Ortynska N., Suberlyak O., 2017
}

around each filler particle which is firmly connected with it, can lead to the new physical phenomena in composite materials.

The aim of this work was to study the regularities and to develop scientific fundamentals of obtaining dispersed-filled hydrogel films based on copolymers of (meth)acrylic esters and functionally active polymeric matrix with selective sorption and diffusion properties which would be suitable for use in pharmacy and medicine as the therapeutic healing systems with the controlled drug release.

\section{Experimental}

The compositions based on 2-hydroxyethylmethacrylate (HEMA) and PVP were the initial materials for the synthesis of polymeric component of composites. Medical PVP (AppliChem GmbH) with a high degree of purification had the molecular weight of 12000 . HEMA (Bisomer) was purified by vacuum distillation, the fraction with $T_{\text {boil }}=351 \mathrm{~K}$ and residual pressure of $130 \mathrm{~N} / \mathrm{m}^{2}$. The initiator potassium persulphate (PPS) was purified by two-fold recrystallization from the aqueous solution. As fillers the following materials were used: aerosil $\mathrm{SiO}_{2}$ (Orisil-200) (specific surface $201 \mathrm{~m}^{2} / \mathrm{g}$; $\left.\rho=0.043 \mathrm{~g} / \mathrm{cm}^{3}\right)$, calcium hydroxyapatite $\mathrm{Ca}_{10}\left(\mathrm{PO}_{4}\right)(\mathrm{OH})_{2}$ (particles diameter $d=50-160 \mu \mathrm{m} ; \rho=3.07 \mathrm{~g} / \mathrm{cm}^{3}$ ), kaolin $\mathrm{Al}_{2} \mathrm{O}_{3} \cdot 2 \mathrm{SiO}_{2} \cdot 2 \mathrm{H}_{2} \mathrm{O}$ (specific surface $15 \mathrm{~m}^{2} / \mathrm{g}$; $\left.\rho=2.58 \mathrm{~g} / \mathrm{cm}^{3}\right)$, zeolite $\mathrm{Na}_{2} \mathrm{O} \cdot \mathrm{Al}_{2} \mathrm{O}_{3} \cdot 2 \mathrm{SiO}_{2} \cdot 1.9 \mathrm{H}_{2} \mathrm{O}$ $\left(d=2-10 \mu \mathrm{m} ; \rho=2.061 \mathrm{~g} / \mathrm{cm}^{3}\right)$, ferromagnetic colloid $\mathrm{Fe}_{3} \mathrm{O}_{4}(d=5-15 \mathrm{~nm})$ and porous granular material "Sferogel" (SG) based on grafted copolymer PHEMA-grPVP $(d=400-650 \mu \mathrm{m})$, which is used as a polymer carrier for controlled drug release [6]. Ferromagnetic colloid $\mathrm{Fe}_{3} \mathrm{O}_{4}$ was synthesized via chemical deposition of $\mathrm{Fe}$ (II) and $\mathrm{Fe}$ (III) salts and $\mathrm{Fe}$ (II) salts oxidation - deposition by the method described in [7]. Granular material "Sferogel" was obtained by a dispersive polymerization following the regimes grounded by previous researches [8]. 
Hydrogel composites in the form of films were obtained via polymerization of HEMA and PVP compositions with fillers in an aqueous medium in the closed glass forms. The polymerization was carried out in an air thermostat with the temperature control accuracy of $\pm 1 \mathrm{~K}$. Two-step mode was used for full completion of the reaction: $323 \mathrm{~K}-2.5 \mathrm{~h} ; 343 \mathrm{~K}-3 \mathrm{~h}$. Before the analysis the films were hydrated in water till achieving an equilibrium state. Unreacted PVP was determined on KFK-3 photoelectric colorimeter using the color filter with $\lambda=590 \mathrm{~nm}$. The method is based on the formation of PVP-iodine colored complex with a quantitative yield. The efficiency of grafting was calculated as the ratio of grafted PVP amount in the copolymer to the total amount of PVP in the basic composition. The grafting degree, $P$, was determined as the ratio of grafted PVP amount to the total weight of the copolymer [9]. Physico-mechanical properties of hydrogel films were determined using "Kimura Machinery" test machine of 050/RT-601U type according to the methods [10].

Saturation of hydrogels with diclofenac sodium was carried out by the following method: previously obtained hydrogel particles were placed in an aqueous solution of the therapeutic substance. When decreasing the concentration in the solution the amount of sorbed drug with polymer particles was assessed. The number of sorbed and desorbed granular remedy with (co)polymers was determined applying the solution conductivity data and chemical method [11]. Measurement of electrical conductivity was conducted via alternating current bridge P5010 using platinum electrodes of comparison. Precalibration of the device was performed by remedy water solutions of known concentrations and calibration graph of dependence $(R=f(C))$ of the solution resistance on the diclofenac sodium concentration was obtained. Measuring of the solution conductivity, the amount of sorbed and desorbed diclofenac sodium was determined through a calibration graph.

\section{Results and Discussion}

The development of polymer predicted synthesis, regulation of its structure and properties are based, in particular, on the kinetics of polymerization. The kinetics is an important factor which significantly determines the physical, chemical and mechanical properties of the final product, and allows to ground scientifically and regulate directionally the technological parameters of polymer synthesis. Thereby, we examined kinetic regularities of HEMA-PVP compositions polymerization in the presence of fine organic and inorganic fillers and determined the effect of basic factors - composite structure, nature and filler concentration, temperature - on polymerization kinetics, structure and properties of copolymers.

Kinetic researches gave the possibility to calculate the main kinetic parameters of HEMA-PVP compositions polymerization in the presence of fillers (Table 1).

The lowest energy parameters of polymerization are observed while using porous polymeric material "Sferogel" (SG) as the filler. Obviously, the additional initiation takes place on the related surface of the porous polymeric filler SG, apart from polymerization initiation by PPS and PVP activating matrix effect [7].

To define the possibility of purposeful regulation of structure and composites properties the interrelations between the basic composition and the composition and structure of the final copolymer have been researched. The grafting parameters and composition of HEMA-PVP copolymers were examined in an aqueous medium in the presence of fillers of different nature. The research results are summarized in Table 2.

The greatest efficiency of PVP grafting is observed while using kaolin filler, and the lowest one - using "Sferogel". A low grafting degree of the last case is an indirect confirmation of received kinetic dependencies when the growth of PHEMA macro chains from "Sferogel" particle surface prevails over HEMA grafting to PVP of the basic composition.

Thus, the polymerization rate and copolymers composition may be directly controlled by the selection of the polymer and monomer compositions, nature and amount of the filler. In such a way one can change the basic operational properties of the synthesized copolymers (Table 3).

Table 1

Kinetic parameters of HEMA-PVP compositions polymerization in the presence of fillers (HEMA+PVP):filler: $\mathrm{H}_{2} \mathrm{O}=10: 2: 10 \mathrm{wt}$. p., [PPS] $=0.3 \mathrm{wt} \%, T=333 \mathrm{~K}$

\begin{tabular}{|c|c|c|c|c|c|c|}
\hline$C_{\text {HEMA }}, \mathrm{mol} / \mathrm{l}$ & HEMA:PVP, wt. $\mathrm{p}$. & Filler & $A_{\max }, \%$ & $V_{p}, \mathrm{~mol} /(\mathrm{l} \cdot \mathrm{s})$ & $K \cdot 10^{2}$ & $E, \mathrm{~kJ} / \mathrm{mol}$ \\
\hline 3.41 & $10: 0$ & HA & 95 & 0.046 & 5.92 & 63 \\
\hline 3.12 & $8: 2$ & HA & 99 & 0.052 & 1.64 & 37 \\
\hline 2.90 & $8: 2$ & SG & 99 & 0.048 & 4.80 & 24 \\
\hline
\end{tabular}

Notes: $A_{\max }-$ monomer boundary conversion; $V_{p}-$ the polymerization velocity; $K$ - reaction rate constant; $E-$ activation energy. 
The influence of filler nature on the efficiency $(f)$, grafting degree $(P)$ and composition of copolymers HEMA:PVP:filler: $\mathrm{H}_{2} \mathrm{O}=$ 8:2:2:10 wt. p., [PPS] $=0.3$ wt $\%, T=333 \mathrm{~K}$

\begin{tabular}{|l|c|c|c|c|}
\hline \multicolumn{1}{|c|}{ Filler } & \multirow{2}{*}{$f, \%$} & \multirow{2}{*}{$P, \%$} & \multicolumn{2}{c|}{ Composition of copolymer, wt \% } \\
\cline { 4 - 5 } & & & PHEMA & PVP \\
\hline Filler free & 91.3 & 18.6 & 81 & 19 \\
\hline Kaolin & 91.2 & 18.9 & 81 & 19 \\
\hline Aerosil & 84.8 & 17.3 & 83 & 17 \\
\hline Hydroxyapatite & 83.4 & 17.1 & 84 & 17 \\
\hline Zeolite & 78.0 & 16.1 & 85 & 16 \\
\hline Ferromagnetic colloid & 74.3 & 15.4 & 88 & 12 \\
\hline "Sferogel" & 56.6 & 12.4 & & 12 \\
\hline
\end{tabular}

Table 3

The properties of composite hydrogel films based on HEMA-PVP copolymers HEMA:PVP: $\mathrm{H}_{2} \mathrm{O}=8: 2: 15$ wt. p.; [PPS] = 0.3 wt \%; $T=323 \mathrm{~K}-2.5 \mathrm{~h} ; T=343 \mathrm{~K}-3 \mathrm{~h}$

\begin{tabular}{|c|c|c|c|c|}
\hline Filler & $\begin{array}{l}\text { Filler content, } \\
\text { wt } \%\end{array}$ & $\begin{array}{c}\text { Tensile strength, } \\
\sigma, \mathrm{MPa}\end{array}$ & $\begin{array}{l}\text { Relative breaking elongation, } \\
\qquad \varepsilon, \%\end{array}$ & $\begin{array}{c}\text { Water content, } \\
W, \%\end{array}$ \\
\hline Filler free & - & 0.39 & 240 & 48 \\
\hline Aerosil & 10 & 1.07 & 73 & 40 \\
\hline Hydroxyapatite & 10 & 0.79 & 140 & 42 \\
\hline Ferromagnetic colloid & 10 & 1.25 & 98 & 45 \\
\hline Kaolin & 10 & 0.81 & 142 & 43 \\
\hline \multirow{3}{*}{ "Sferogel" } & 5 & 0.89 & 149 & 53 \\
\hline & 10 & 1.03 & 88 & 52 \\
\hline & 15 & 1.12 & 86 & 51 \\
\hline Zeolite & 10 & 0.65 & 134 & 57 \\
\hline
\end{tabular}

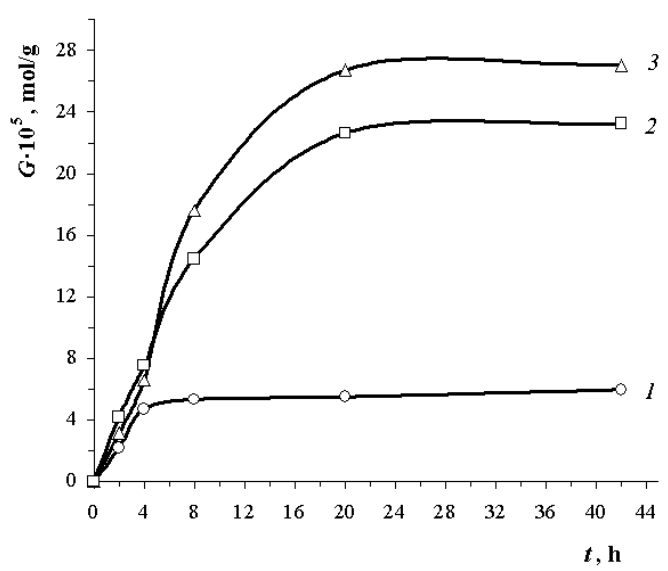

Fig. 1. The kinetic curves of diclofenac sodium sorption $(G)$ by granulated hydrogel polymer (SG): HEMA:PVP, wt. p.: 1 - 10:0 (SG-1); 2 - 8:2 (SG-2); 3 - 7:3 (SG-3); $d=640 \mu \mathrm{m}$

The significant increase in strength is observed for all filled film composites compared with the basic hydrogel. The ferromagnetic colloid and "Sferogel" filled films have the highest strength during film stretching but their elasticity (relative breaking elongation) is lower in the case of SG filling. The most elastic are hydrogel films filled with zeolite and hydroxyapatite. The hydrogel films filled with SG and zeolite are characterized by high equilibrium water content but introduction of colloidal

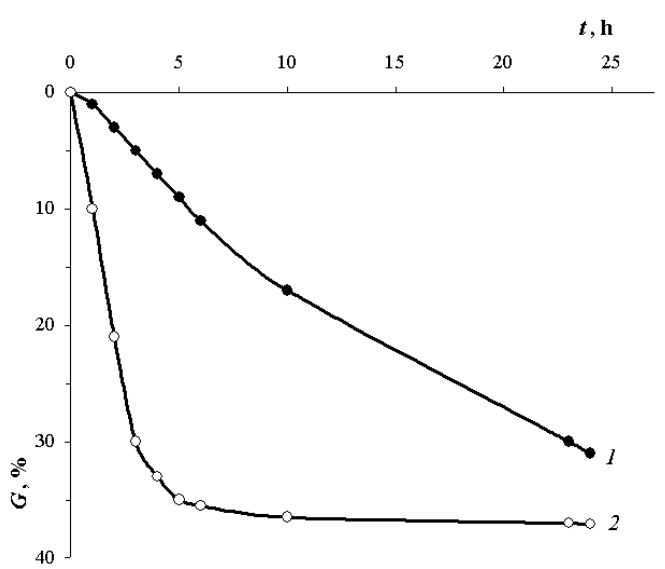

Fig. 2. Kinetic curves of diclofenac sodium desorption: 1 - for film composite materials filled with SG

(HEMA:PVP:SG-2: $\mathrm{H}_{2} \mathrm{O}=8: 2: 1: 15$ wt. p.) $; 2$ - for $\mathrm{SG}-2$

silica and hydroxyapatite causes the films water absorption decreasing compared with unfilled hydrogels.

Thus, the introduction of porous dispersed fillers into acrylic hydrogels allows to obtain films with advanced strain-strength characteristics, which vary depending on the nature of the filler within a wide range: tensile strength $0.7-1.25 \mathrm{MPa}$; the relative breaking elongation of the film $70-150 \%$ depending on the filler nature and amount. The water absorption of hydrogel membranes filled with 
inorganic fillers is much lower than those filled with SG. Moreover, the mechanical strength of filled hydrogel films does not proportionally depend on their water content, but mainly on the filler type and amount.

As one of the possible and important directions of applying synthesized composite films are polymer systems with prolonged drug release, so it was important to research the sorption-desorption properties of the films relative to drugs. For research the composite hydrogel films filled with granular material "Sferogel" which was previously saturated by diclofenac sodium have been applied. This specimen is an effective anti-inflammatory agent, but has negative side effects. Therefore, the reduction of the single-dose quantity without decreasing its effective action is an urgent problem.

Diclofenac sodium is applied as an antiphlogistic, antipyretic and analgesic remedy which is not suitable for a stomach ulcer. Besides, prolonged use can change the blood formula. Therefore, important is the creation of such a long-acting drug that will significantly reduce the proportion of the effective use and minimize its negative effect on the mucosa of the esophagus and stomach.

We researched the effect of main components ratio of the initial composition on sorption-desorption properties of the granulated polymers based on them, the results of which are shown in Fig. 1.

As seen, from the obtained results, the lowest observed sorption capacity has homopolymers based on HEMA (Fig. 1, curve 1). The efficient sorption is observed already for the first $4 \mathrm{~h}$ of the process and further it remains practically unchanged. Introduction of PVP links into the copolymer composition considerably increases both sorption rate and limited amount of the sorbed drug. There are several reasons for this fact, the main of which is appearance of the additional functional groups of different nature $(\mathrm{N}-\mathrm{C}=\mathrm{O})$ in the copolymer and the increase of granule porosity. It is known $[9,10]$ that some part of the PVP during hydration is able to be washed out. At the same time the formed space is filled with water or saline solution and substances dissolved in them. Thus, the regulation ratio of HEMA and PVP links allows to change the copolymers sorption properties in the right direction.

An important task in the given work was also to research the processes of drug release by spherical parts, since they model the behavior of prolonged drug form during the operation.

The granulated drugs carriers of "Sferogel" provide an effective control of release at a constant rate during the first 8-10 h (Fig. 2, curve 2).

If the granules are placed in a hydrogel film the induction period of 1 hour is observed during release when the drugs diffuse from the granules through the film, in this case the stable and prolonged release takes place into the environment during the day (Fig. 2, curve 1).

\section{Conclusions}

The fillers were selected and films hydrogel composites based on copolymers of polyvinylpyrrolidone with 2-hydroxyethylmethacrylate were synthesized. The technological characteristics of their formation were investigated as well. The polymerization kinetics of HEMA-PVP compositions in the presence of fine fillers and the initial effect of the "Sferogel" polymer filler on the polymerization and copolymer composition were examined. The best physico-mechanical properties were observed for the composite hydrogel films based on HEMA-PVP copolymers and filled with "Sferogel" porous polymeric filler, when its amount in the composition was substantial. The results obtained confirm the perspective for the synthesized composite polymers based on HEMA-PVP copolymers, especially in developing of therapeutic healing films with the controlled drug release.

\section{References}

[1] Skorokhoda V., Semenyuk N., Kostiv U. et al.: Chem. Chem. Technol., 2013, 7, 95.

[2] Skorokhoda V., Semenyuk N., Melnyk Y. et al.: Chem. Chem. Technol., 2009, 3, 117.

[3] Melnyk Y., Halyshyn O., Skorokhoda V.: Khim. Prom. Ukrainy, 2009, 4, 26.

[4] Melnyk Y., Semenyuk N., Yatsulchak G. et al.: Composite Polymer Hydrogels with Prolonged Drug Release [in:] Novikov V. (Ed.), Modern Directions in Chemistry, Biology, Pharmacy and Biotechnology. Lviv Polytechnic PH, Lviv 2015, 179.

[5] Menson J., Sperlinh L. Polimiernyye Smiesi i Kompozity. Khimiya, Moskva 1979.

[6] Skorokhoda V., Semenyuk N., Lukan G. et al.: Polym. J., 2006, 2, 155 .

[7] Semenyuk N.: Khim. Prom. Ukrainy, 2008, 1, 35.

[8] Suberlyak O., Semenyuk N., Dudok G. et al.: Rus. J. Appl. Chem., 2012, 85, 830. https://doi.org/10.1134/S1070427212050254

[9] Suberlyak O., Skorokhoda V., Semenyuk N.: Eng. Biomater., 2007, 63-64, 14.

[10] Suberlyak O., Melnyk Y., Skorokhoda V.: Mater. Sci., 2015, 50, 889. https://doi.org/10.1007/s11003-015-9798-8

[11] Turkevych M.: Farmacevtychna Khimiya. Vyshcha shkola, Kyiv 1973.

Received: October 26, 2016 / Revised: November 10, 2016 / Accepted: J anuary 19, 2017

\section{ПЛІВКОВІ ГІДРОГЕЛІ НА ОСНОВІ КОПОЛІМЕРІВ ПОЛІВІНІЛПІРОЛІДОНУ З РЕГУЛЬОВАНИМИ СОРБЦЙНО-ДЕСОРБЦЙНИМИ ХАРАКТЕРИСТИКАМИ}

Анотація. Синтезовано гідрогелеві плівкові композити біомедичного призначення на основі кополімерів полівінілпіролідону з 2-гідроксіетилметакрилатом. Встановлено вплив природи, кількості наповнювача та складу композииії на закономірності одержсання, структуру та властивості гідрогелів. Синтезовані гідрогелеві композити рекомендовані для використання для систем із контрольованим вивільненням ліків.

Ключові слова: гідрогель, полівінілпіролідон, 2-гідроксіетилметакрилат, наповнювач, сорбиія, вивільнення. 